Brindaban C. Ranu*, Laksmikanta Adak* and Tubai Ghosh

\title{
Learning Green Chemistry and its principles from Nature's process and development of green procedures mimicking nature
}

https://doi.org/10.1515/cti-2021-0023

Received August 23, 2021; accepted October 30, 2021; published online November 12, 2021

\begin{abstract}
We have highlighted an example of a natural process like photosynthesis to introduce the subject of Green Chemistry. Photosynthesis can be an ideal example to illustrate a green process explaining all the features such as selection of raw materials, solvent, catalyst, energy, etc. for an environment-friendly reaction. From the same reaction, all the principles of Green Chemistry can be derived in a simpler way without the need of memorizing these in a set language. In this article, a few examples of green procedures for the synthesis of useful molecules have been illustrated in light of the knowledge of photosynthesis. The visible-light mediated reactions, organic reactions in water, and solvent-free organic reactions are discussed here for a practical illustration of Green synthesis.
\end{abstract}

Keywords: green chemistry; green synthesis; organic reactions in water; solvent-free organic reactions; visible-light mediated reactions.

\section{Introduction}

'Green Chemistry' is a philosophy to provide guidelines to prevent chemical pollution in the environment. The primary objective is to design a process to reduce or remove the use and/or the production of hazardous substances from the initial stage (Ahluwalia, 2013; Bryan et al., 2018; Deligeorgiev et al., 2010; Tang, Smith, \& Poliakoff, 2005). Although the definition of Green Chemistry and its 12 principles are well set showing the direction on the groundwork of this area of research, the students often find it difficult to remember them correctly. Alternatively, if they are given an example of a common natural process like photosynthesis and the salient features of this reaction are described to explain the basic principles of green synthesis, they might be more interested. Photosynthesis can be an ideal example to explain a green process explaining all the parameters such as raw materials, solvent, catalyst, energy used there (Figure 1).

To illustrate, the starting materials used in this reaction are carbon dioxide and water that are cheap, abundant and nontoxic. On the other hand, the products are glucose and oxygen that are immensely useful and environment friendly. The catalyst and solvent used in this reaction are nontoxic chlorophyll and water and the energy employed is sunlight. Thus, if we follow this reaction we find that the reactants and products are non-hazardous and environment friendly. The catalyst, solvent and energy are also nontoxic. Thus this process does not use and produce any harmful chemical. In practice, these are the basic principles of Green Chemistry. On deeper analysis, the reaction is energy-efficient, atom economic, cost effective, safe and sustainable. In addition, this operation does not involve any protection-deprotection technique. Thus, this

\footnotetext{
*Corresponding authors: Brindaban C. Ranu, School of Chemical Sciences, Indian Association for the Cultivation of Science, Jadavpur, Kolkata 700032, India, E-mail: ocbcr@iacs.res.in; and Laksmikanta Adak, Department of Chemistry, Indian Institute of Engineering Science and Technology, Shibpur, Botanic Garden, Howrah 711103, India, E-mail: ladak@chem.iiests.ac.in Tubai Ghosh, Department of Chemistry, Jadavpur University, Kolkata 700032, India
}

Ә Open Access. ( 2021 Brindaban C. Ranu et al., published by De Gruyter. (c) BY-NC-ND This work is licensed under the Creative Commons Attribution-NonCommercial-NoDerivatives 4.0 International License. 


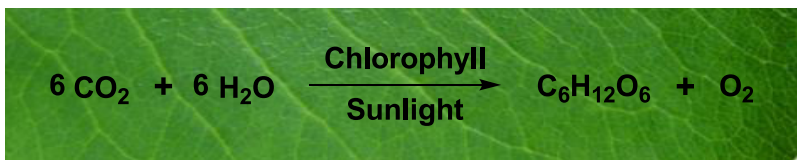

Figure 1: Photosynthesis.

natural process teaches us all the principles of Green Chemistry in a simpler way without the need of memorizing these in a set language. We believe, Green Chemistry can be introduced based on a natural process like photosynthesis, which may be readily acceptable to the students.

A few examples of green procedures for the synthesis of useful molecules has been illustrated in the light of knowledge of photosynthesis. The visible-light mediated synthesis, organic reactions in water and solvent-free organic reactions will be discussed here for practical illustration of Green Chemistry.

Light can be efficiently utilized for benign, 'green' chemical synthesis. Photocatalysis has emerged as an enabling technology in organic synthesis (Douglas, Sevrin, \& Stephenson, 2016; Li, Terrett, \& Zbieg, 2020) because of its demonstrated operational simplicity, biocompatibility, potential for wide-ranging functional group tolerance, and site-specific selectivity.

Water as solvent is one of the most potent tool of green synthesis as it reduces emission of toxic chemicals in the environment (Cortes-Clerget et al., 2021; Li \& Chen, 2006; Ruiz-Lopez, Francisco, Martins-Costa, \& Anglada, 2020). Moreover, water has been found to accelerate many reactions and the reaction rate became much faster than those in organic solvents (Cortes-Clerget et al., 2021; Ruiz-Lopez et al., 2020).

Many conventional chemical processes involve large amounts of volatile and toxic organic solvents and this posed a serious health problem to the workers, other than environmental pollution. Thus, reaction in the absence of hazardous organic solvents is a desirable step and the design of solvent-free procedures has received considerable attention towards a green development (Sarkar et al., 2016; Zangade \& Patil, 2019).

Inspired by Mother Nature's procedure and following the green parameters of photosynthesis (sunlight as energy source, water as solvent, atom economy and cost effectivity) some representative reactions performed under visible-light mediated photocatalysis, in water and in the absence of hazardous organic solvent, are highlighted here leading to the synthesis of useful molecules by green protocols.

\section{Visible-light mediated reactions}

Visible light mediated photoredox catalysis has become a powerful tool for the synthesis of organic molecules. Unlike thermal process, visible light photocatalysis occurs under mild condition and do not require radical initiators or equivalent amount of hazardous oxidants. Under visible light irradiation, catalyst undergoes to its excited state and can function as a single-electron redox mediator via SET (single electron transfer) process and facilitate energy transfer to activate a wide range of molecules which then take part in previously inaccessible organic transformations. Typical irradiation involves sunlight, LEDs and household lamps which are cheaper and easier to apply, and makes it much more economical and environment friendly (Festa, Voskressensky, \& Van der Eycken, 2019; Kärkäs, Porco, \& Stephenson, 2016; Li, Xu, Xie, Yu, \& Zhu, 2018; Silvi \& Melchiorre, 2018; Skubi, Blum, \& Yoon, 2016). In this part, we have mainly focussed on the synthesis of simple organic molecules under visible light photocatalysis at room temperature starting from easily accessible materials.

The photoreduction of benzophenone to benzopinacol is one of the first studied photochemical reactions. It was discovered that benzopinacol could be prepared from benzophenone in presence of sunlight (photochemically) using isopropanol as the reducing agent in the presence of a small drop of glacial acetic acid (Figure 2) (Bachmann, 1934; Lampman \& Chriz, 1982). Acetic acid is added to prevent the cleavage of benzopinacol to benzophenone and benzhydrol by the alkali derived from the glass container used for the 
2<smiles>O=C(c1ccccc1)c1ccccc1</smiles><smiles>CCOC(=O)OC</smiles><smiles>OC(c1ccccc1)(c1ccccc1)C(O)(c1ccccc1)c1ccccc1</smiles>

Figure 2: Photoreduction of benzophenone to benzopinacol.

reaction. This reaction protocol mimics nature and is thus endowed with several green benefits such as, use of safe chemicals, safer reaction conditions, and use of renewable source of energy (solar energy).

The reaction mechanism for photoreduction is outlined in Figure 3. It is well known that the reaction of $n-\pi^{\star}$ triplet state $\left(T_{1}\right)$ of benzophenone is responsible for the photoreduction of benzophenone. The $n-\pi^{\star}$ excited states have radical character at the carbonyl oxygen atom because of the unpaired electron in the nonbonding orbital. Hence, the energetic and radical-like $\mathrm{T}_{1}$ excited-state species can take a hydrogen atom from an appropriate hydrogen-donor solvent to form the diphenyl hydroxymethyl radical. Subsequently, two of these radicals couple to form benzopinacol.

Experimental procedure: Benzophenone (2.5 g), taken in a test tube was dissolved in 2-propanol $(10 \mathrm{~mL})$ under warm condition in a water bath. Then a drop of glacial acetic acid was added to it and the test tube was filled with 2-propanol. The test tube was exposed to bright sun light. Colorless crystals of benzopinacol started appearing along the sides of the test tube after 5-6 h. The reaction mixture was allowed to stand in bright sunlight for a longer period for the completion of the reaction. The solid product was filtered, washed and dried (m.p. $\left.182-184^{\circ} \mathrm{C}\right)$.

A sun light assisted direct synthesis of amide by the reaction of carboxylic acid and amines was demonstrated (Figure 4) (Cohen et al., 2017). The reaction occurs via the formation of a charge transfer complex between amine and carbon tetrachloride which then activates the amine for the photochemical reaction. Both aromatic and aliphatic carboxylic acids reacted with triethylamine in the presence of $\mathrm{K}_{2} \mathrm{CO}_{3}$ in a mixed solvent of $\mathrm{CCl}_{4}$ and $\mathrm{CH}_{2} \mathrm{Cl}_{2}$ (3:1 ratio) under the exposure of sunlight at room temperature and the corresponding amides were obtained in good yields. The reaction was scaled up with multigram quantities.

Representative experimental procedure for the preparation of visible light mediated amides: A mixture of carboxylic acid ( 1 equivalent), amine (7.5 equivalents) and $\mathrm{K}_{2} \mathrm{CO}_{3}$ (6.8 equivalents) in a mixed solvent of $\mathrm{CCl}_{4}(6.9 \mathrm{M})$ and $\mathrm{CH}_{2} \mathrm{Cl}_{2}(3.6 \mathrm{M})$ was degassed using $\mathrm{N}_{2}$ or argon. The reaction mixture was stirred under sun light for the required time (TLC). Upon completion, the reaction was acidified with $1 \mathrm{M}$ solution of $\mathrm{HCl}$ and extracted with $\mathrm{CH}_{2} \mathrm{Cl}_{2}$. The organic extracts after being dried over anhydrous $\mathrm{Na}_{2} \mathrm{SO}_{4}$ was evaporated under reduced pressure to leave a crude product which was purified by column chromatography to furnish the corresponding amide as a pure product.

A procedure for the direct $\mathrm{C}-\mathrm{H}$ arylation of the pyridine and other $\mathrm{N}$-heteroarenes with aryl diazonium tetrafluoroborates, in water, using visible-light irradiation (blue-LED) in the absence of any photocatalyst was developed (Figure 5) (Bartolomeu, Silva, Brocksom, Noël, \& Oliveira, 2019). Several substituted aryl diazonium

$$
\begin{aligned}
& \mathrm{Ph}_{2} \mathrm{C}=\mathrm{O} \stackrel{h v}{\longrightarrow} \mathrm{Ph}_{2} \dot{\mathrm{C}}-\dot{\mathrm{O}}\left(\mathrm{S}_{1}\right) \stackrel{\text { isc }}{\longrightarrow} \mathrm{Ph}_{2} \dot{\mathrm{C}}-\dot{\mathrm{O}}\left(\mathrm{T}_{1}\right)
\end{aligned}
$$

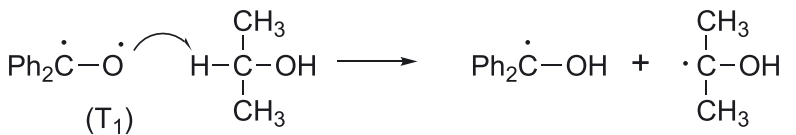

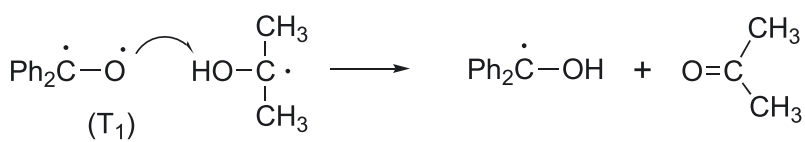

$$
\begin{aligned}
& 2 \mathrm{Ph}_{2} \dot{\mathrm{C}}-\mathrm{OH} \longrightarrow \\
& \begin{array}{c}
\mathrm{OH} \\
\mathrm{I} \\
\mathrm{Ph}-\mathrm{I} \\
\stackrel{\mathrm{C}}{\mathrm{C}}-\mathrm{C}-\mathrm{Ph} \\
\mathrm{Ph} \stackrel{\mathrm{Ph}}{\mathrm{Ph}}
\end{array}
\end{aligned}
$$

Figure 3: Mechanism for photoreduction. 


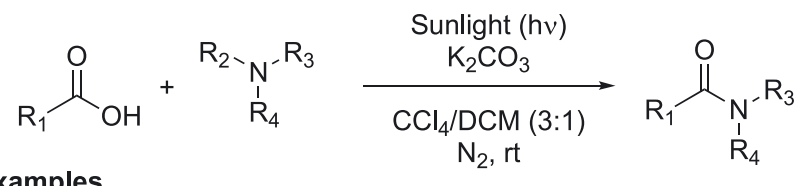

Selective Examples<smiles>CCN(CC)C(=O)c1ccccc1</smiles>

$83 \%, 24 \mathrm{~h}$<smiles>O=C(c1ccc2ccccc2c1)N1CCCC1</smiles>

$83 \%, 24 \mathrm{~h}$<smiles>CCN(CC)C(=O)/C=C/c1ccccc1</smiles>

$65 \%, 22 \mathrm{~h}$

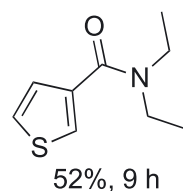

$52 \%, 9 \mathrm{~h}$<smiles>CCN(CC)C(=O)c1ccncc1</smiles>

$69 \%, 29 \mathrm{~h}$<smiles>CCN(CC)C(=O)Cc1ccccc1</smiles>

$79 \%, 21 \mathrm{~h}$
Figure 4: Sunlight driven synthesis of amides.

tetrafluoroborates containing electron-neutral, -donor, and -acceptor groups underwent this reaction with substituted pyridines, quinoxaline, and quinoline at room temperature.

A plausible mechanism for the visible-light-induced direct $\mathrm{C}-\mathrm{H}$ arylation of pyridines is shown in Figure 6. The aryl diazonium salt reversibly associates with the free pyridine/heterocycle to produce the electron donor-acceptor (EDA) complex, which absorbs blue light and generates the aryl radical in the excited state. Subsequently, the aryl radical reacts with the pyridinium salt to produce a new radical intermediate that is successively aromatized by reaction with oxygen gas. It was established that the oxygen atmosphere has a vital role in increasing the yields. Ultimately, aqueous work-up provided the required arylated heterocycles.

Representative experimental procedure for the preparation of 2-(4-methoxyphenyl)pyridine: The solution of pyridine hydrochloride $(7.5 \mathrm{mmol}$, 15 equivalent $)$ in $\mathrm{H}_{2} \mathrm{O}(1.5 \mathrm{~mL})$ was sonicated to eliminate the dissolved air and was saturated with pure $\mathrm{O}_{2}$ by $10 \mathrm{~min}$ of bubbling the gas. The 4-methoxybenzenediazonium tetrafluoroborate $(0.5 \mathrm{mmol}, 1$ equivalent) was quickly added to the purged solution. The reaction mixture was stirred under an oxygen atmosphere (balloon) at room temperature for $48 \mathrm{~h}$ being irradiated with a $30 \mathrm{~W}$ blue LED lamp. Then the reaction mixture was quenched with saturated aqueous $\mathrm{NaHCO}_{3}(10 \mathrm{~mL})$ and extracted with EtOAc $(3 \times 20 \mathrm{~mL})$. The organic extract was washed with brine $(1 \times 10 \mathrm{~mL})$, dried over $\mathrm{Na}_{2} \mathrm{SO}_{4}$,

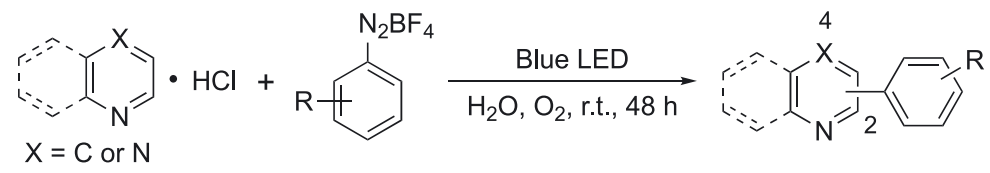

Selective Examples

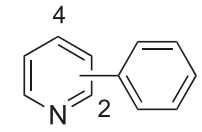

$62 \%$

2-aryl/4-aryl, 71:29

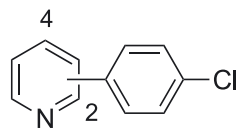

$80 \%$

2-aryl/4-aryl, 68:32

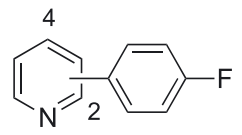

$53 \%$<smiles>O=[N+]([O-])c1ccc(C2=CC=CN=I2)cc1</smiles>

$66 \%$ 2-aryl/4-aryl, 64:36<smiles>FC(F)(F)c1cccc(C2=CC=CN=[In]2)c1</smiles>

$49 \%$

2-aryl/4-aryl, 63:37<smiles>Cc1ccc(C23C=CC=CN2C=CC=C3)cc1</smiles>

$80 \%$

2-aryl/4-aryl, 68:32<smiles>COc1ccccc1-c1cccnc1</smiles>

$57 \%$

2-aryl/4-aryl, 66:34<smiles>COc1ccc(-c2cc(C(F)(F)F)ccn2)cc1</smiles><smiles>COc1ccc(-c2cnc3ccccc3n2)cc1</smiles>

Figure 5: Photoarylation of pyridines using aryldiazonium salts and visible light. 


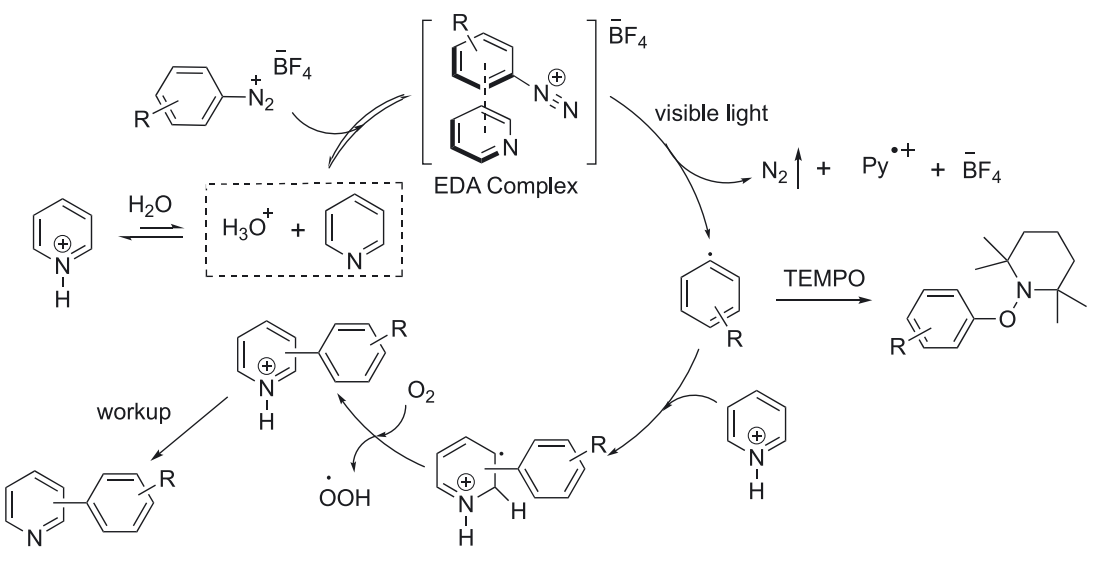

arylated $\mathrm{N}$-heteroarenes

Figure 6: Plausible mechanism for the visible-light-induced $\mathrm{C}-\mathrm{H}$ arylation of pyridines.

and was concentrated under vacuum. The crude product was purified by silica gel column chromatography to afford 2-(4-methoxyphenyl)pyridine in $68 \%$ yield $(63.2 \mathrm{mg})$ as a yellow solid. m.p. $51-53^{\circ} \mathrm{C}$.

A unique process for the formation of $\mathrm{C}-\mathrm{C}$ bond by visible light photocatalytic coupling of 1,4-dihydropyridines bearing different substituents in ethanol was reported (Figure 7) (Chen et al., 2020). The visible-light-induced activated $\mathrm{C}-\mathrm{H}$ bond is used for this selective construction of new $\mathrm{C}-\mathrm{C}$ bonds. This method has several green features, such as no use of catalyst and solvent and use of visible light as energy source.

A plausible reaction pathway is shown in Figure 8. Under blue-LED light irradiation, the methylene in the para position is activated to a single electron methyl radical which with a strong tendency to pair electrons, dimerizes with another single electron methylene to form a new $\mathrm{C}-\mathrm{C}$ bond.

Representative procedure for synthesis of $1,1^{\prime}$-dibenzyl-3, $3^{\prime}$-dicyano-1,1',4,4'-tetrahydro4,4'-bipyridine: A solution of 1-benzyl-3-cyano-1,4-dihydropyridine $(5 \mathrm{mmol})$ in absolute ethanol $(25 \mathrm{~mL})$ taken in a three-necked quartz round bottomed flask was irradiated with the light source, Argon protection LED with a wavelength of $410 \mathrm{~nm}$ for three days (TLC). The solvent was removed under reduced pressure and the crude reaction product was purified by silica gel column chromatography (petroleum ether/ethyl acetate
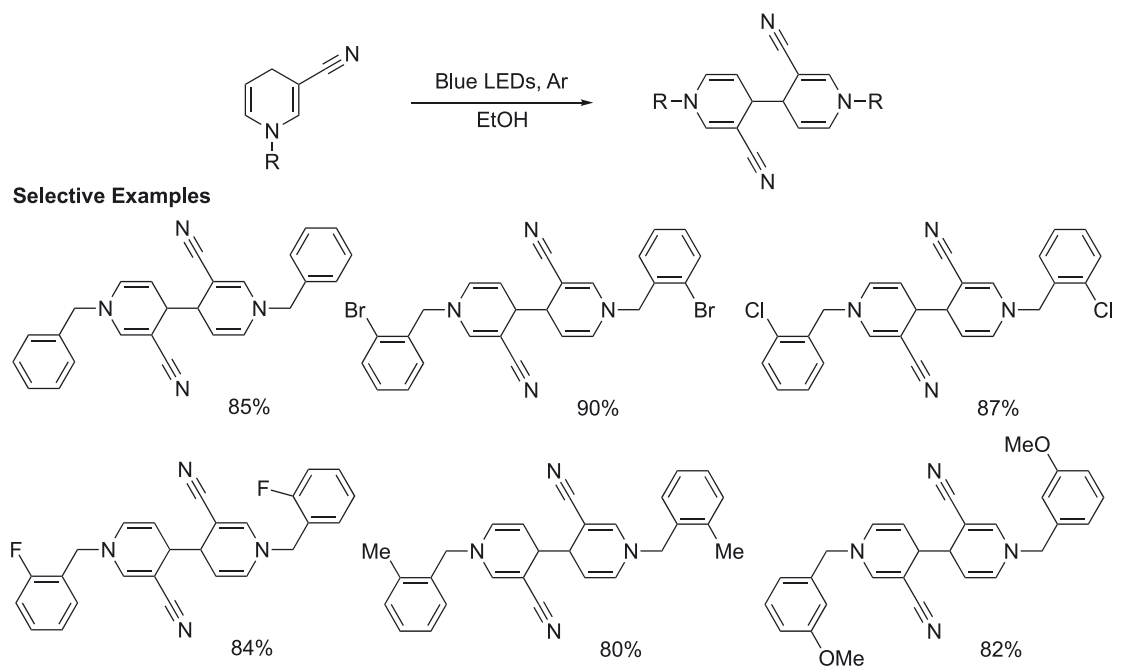

Figure 7: Coupling reaction of 1,4-dihydropyridine derivatives under photocatalytic conditions. 


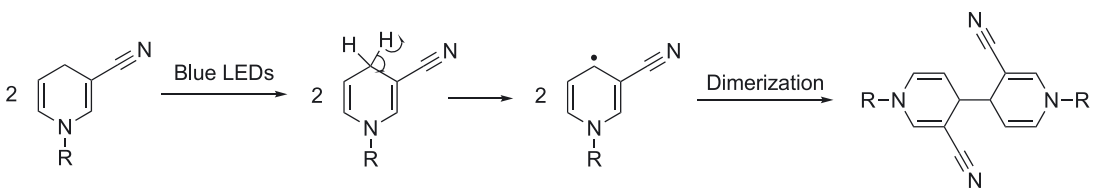

Figure 8: Proposed mechanism.

ratios of $4: 1-5: 1)$ to produce the product $1,1^{\prime}$-dibenzyl-3,3'-dicyano-1,1',4,4'-tetrahydro-4, $4^{\prime}$-bipyridine, m.p. $145-146^{\circ} \mathrm{C}$ (from $\mathrm{CH}_{3} \mathrm{OH}$ ).

\section{Organic reactions in water}

Water is the solvent of choice by nature to carry out her own synthesis (Ball, 2000). Water is also appreciated as solvent for organic synthesis due to its abundance, cost-efficiency, availability, nontoxicity, nonflammability and environmental concerns (Kitanosono, Masuda, Xu, \& Kobayashi, 2018; Li, 1993; Lindstrom, 2002). However, water has been less extensively used as a solvent for syntheses till the beginning of 1980 because of the low solubility of organic molecules and the facile decomposition of active species in water. Thus, usually organic reactions have been performed in non-polar or polar organic solvents (Riddick, Bunger, \& Sakano, 1986). This situation has changed since the pioneering work of Breslow (Breslow, 1991; Rideout \& Breslow, 1980).

Breslow and his coworker observed that the acceleration of the Diels-Alder reaction between cyclopentadiene and butenone in water was owing to the hydrophobic effect. Actually, the rate of the reaction in water was 58-fold and more than 700-fold higher than in methanol and hydrophobic solvents, respectively (Figure 9) (Breslow, 1991; Rideout \& Breslow, 1980).

In 2005, Sharpless also noticed the remarkable acceleration of the reaction rate using water as the reaction medium (Narayan et al., 2005). A few examples for the synthesis of useful molecules in water are highlighted here to illustrate the efficacy of water as reaction medium and catalyst.

Ranu and Banerjee (2007) reported a simple procedure for the aza-Michael addition in water without any catalyst or organic solvent (Figure 10). This procedure offers an efficient methodology for the synthesis of $\beta$-amino carbonyl compounds, which are useful intermediates for the synthesis of a range of biologically important natural products, $\beta$-amino alcohols and other nitrogen-containing molecules (Cardillo \& Tomasini, 1996). At room temperature, several primary and secondary amines underwent easy additions with $\alpha, \beta$-unsaturated carboxylic esters, nitriles, ketones and amides in water. The results are summarized in Figure 10.

In general, the reactions are very clean and provide high yield of products. All the reactions in water were very fast (20-50 $\mathrm{min}$ ) compared to the reactions in organic solvents using catalysts which were reported to take longer periods (2-8 h) (Azizi \& Saidi, 2004; Basu, Das, \& Hossain, 2004; Loh \& Wie, 1998; Reboule, Gil, \& Collin, 2005; Surendra, Krishnaveni, Sridhar, \& Rao, 2006; Varala, Alam, \& Adapa, 2003; Xu, Li, Zhou, \& Xia, 2004).

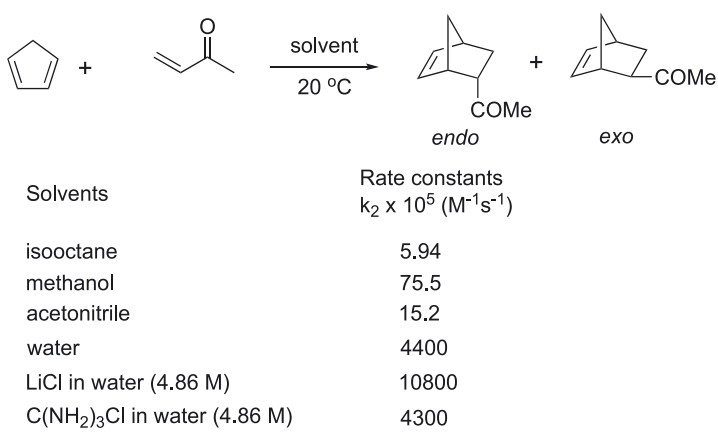

Figure 9: Diels-Alder reaction accelerated by on water condition (Breslow). 


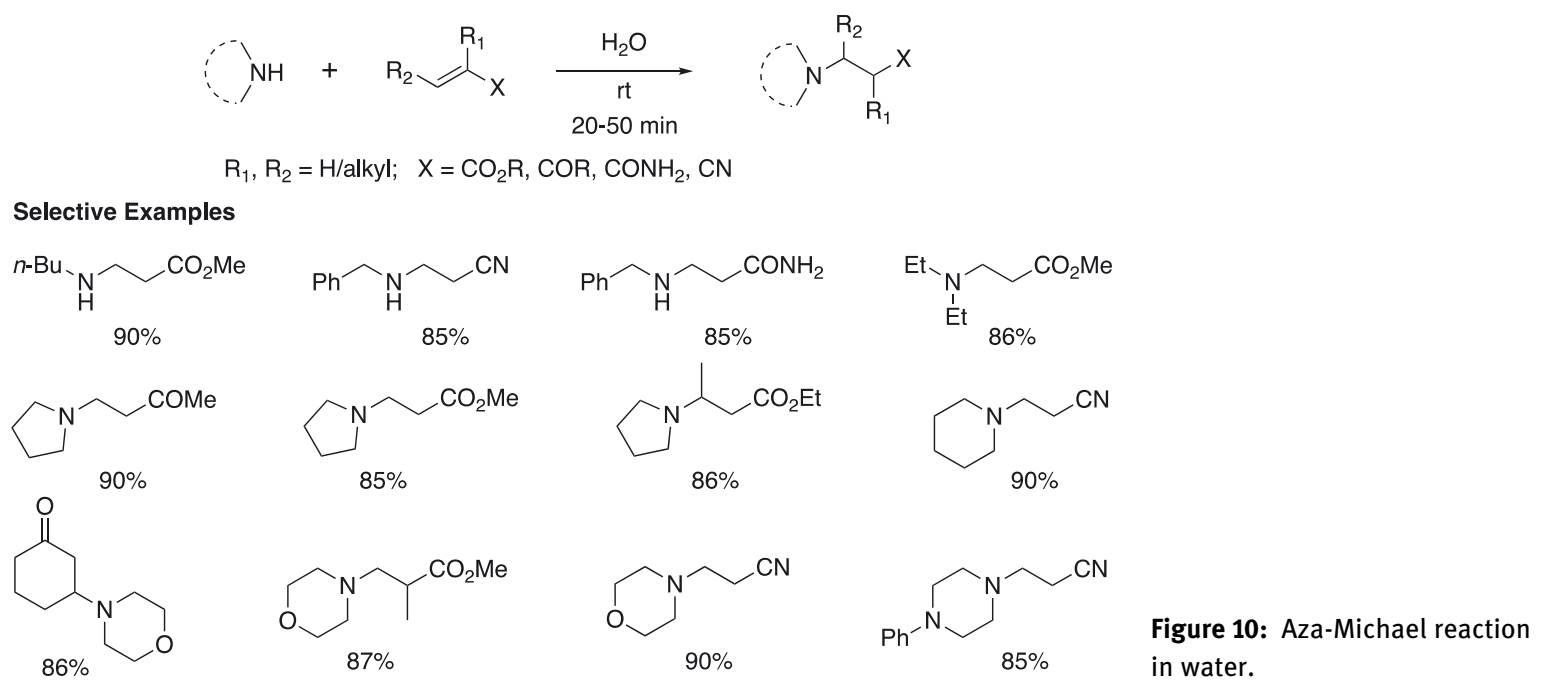

A possible mechanism for aza-Michael addition reaction in water was shown in Figure 11. Water forms hydrogen bond with the carbonyl oxygen atom of the $\alpha, \beta$-unsaturated carbonyl compound and this increases the electrophilic character at the $\beta$-carbon, which is attacked by the nucleophilic amine. On the other hand, the oxygen atom of water forms hydrogen bond with the $\mathrm{H}$-atom of the amine and the nucleophilic character of the $\mathrm{N}$ atom of amine is increased. Thus, water activates the conjugated alkene as well as the amine and thus significantly facilitates the addition.

Representative experimental procedure for the preparation of 3-pyrrolidin-1-yl-propionic acid methyl ester: A mixture of methyl acrylate $(130 \mathrm{mg}, 1.5 \mathrm{mmol})$ and pyrrolidine $(71 \mathrm{~g}, 1 \mathrm{mmol})$ in water $(1 \mathrm{~mL})$ was stirred at room temperature for $20 \mathrm{~min}$ until completion as indicated by TLC. The reaction was found to be slightly exothermic; however no temperature control was necessary for laboratory scale quantities. The reaction mixture was extracted with ethyl acetate $(2 \times 10 \mathrm{~mL})$ and the combined extract after being dried $\left(\mathrm{Na}_{2} \mathrm{SO}_{4}\right)$, was evaporated to leave a crude product, which was purified by column chromatography over silica gel to provide a colorless oil (150 mg, 85\%), 3-pyrrolidin-1-yl-propionic acid methyl ester (IR, ${ }^{1} \mathrm{H}$ and ${ }^{13} \mathrm{C} \mathrm{NMR}$ ) (Azizi \& Saidi, 2004).

Vasuki and Kumaravel reported a four-component reaction for a combinatorial synthesis of highly functionalized 4-pyrazolyl-4H-chromene frameworks at ambient temperature in water in the absence of any catalyst (Figure 12) (Kumaravel \& Vasuki, 2009). The chromene skeleton (Ellis, 1997), particularly 4-aryl/ alkyl-2-aminochromenes, is an important medicinal scaffold. Several compounds containing pyrazolone unit are also employed as antipyretics, analgesics etc. Thus, a molecular framework combining chromene and pyrozolone moieties might acquire the properties of both and enhance the activity.<smiles>[R]C(=O)C=C</smiles>

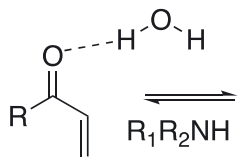<smiles></smiles><smiles>[R]C(=O)CCN([R])C</smiles><smiles>[R]/C(O)=C\CN([R6])CC</smiles>

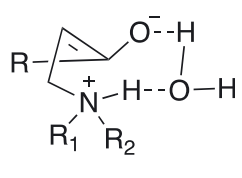

Figure 11: Mechanism: dual action of water during the aza-Michael reaction. 


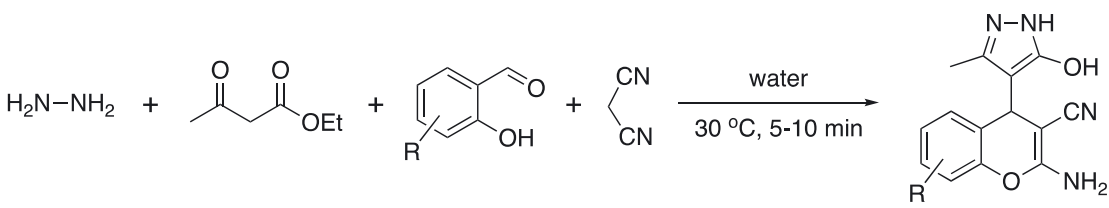

Selective Examples<smiles>Cc1n[nH]c(O)c1C1C(C#N)=C(N)Oc2ccccc21</smiles>

$87 \%$<smiles>COc1ccc2c(c1)C(c1c(C)n[nH]c1O)C(C#N)=C(N)O2</smiles>

$78 \%$<smiles>Cc1n[nH]c(O)c1C1C(C#N)=C(N)Oc2ccc([N+](=O)[O-])cc21</smiles>
$86 \%$<smiles>Cc1cc(C)c2c(c1)OC(N)=C(C#N)C2c1c(C)n[nH]c1O</smiles>

$76 \%$<smiles>Cc1n[nH]c(O)c1C1C(C#N)=C(N)Oc2ccc(Br)cc21</smiles>

$92 \%$<smiles>Cc1n[nH]c(O)c1C1C(C#N)=C(N)Oc2c(Br)cc(Br)cc21</smiles><smiles>Cc1n[nH]c(O)c1C1C(C#N)=C(N)Oc2ccc(O)cc21</smiles>

$79 \%$<smiles>Cc1cc2c(cc1Cl)C(c1c(C)n[nH]c1O)C(C#N)=C(N)O2</smiles>

Figure 12: Catalyst-free synthesis of 4-pyrazolyl-4H cromene in water.

Novel pyrazolyl-4H-chromene derivatives were synthesized in good to excellent yields by a fourcomponent reaction of hydrazine hydrate, ethyl acetoacetate, 2-hydroxybenzaldehyde and malononitrile in water at ambient temperature. The products were isolated by filtration of the reaction mixture. Recrystallization or usual chromatographic purification was usually not required. However, the products were washed with distilled water and then with a small amount of an ethyl acetate/hexane mixture (1:1) to get pure compounds.

The mechanism for the formation of product is shown in Figure 13. Formation of the product is proposed to comprise the tandem reactions of: (i) reaction between hydrazine hydrate and ethyl acetoacetate resulting in instantaneous formation of pyrazolone, (ii) Knoevenagel reaction between 2-hydroxybenzaldehyde and malononitrile producing 2-imino- $2 \mathrm{H}$-chromene-3-carbonitrile intermediate by 6-exo-dig cyclization of the hydroxyl group with the cyano group, and (iii) Michael addition of pyrazolone to 2-imino- $2 \mathrm{H}$-chromene3-carbonitrile and subsequent rearrangement. The reaction is completed within 5-10 min. The pyrazolone moiety is present as a hydroxyl tautomer in the product.

The green aspects of this reaction protocol include: (a) high atom economy, (b) ethanol and water as the byproducts, (c) water as the reaction medium, (d) avoidance of catalyst and hazardous organic solvent, and (e) step economy being a multi-component reaction.

General experimental procedure: Malononitrile $(0.132 \mathrm{~g}, 2 \mathrm{mmol})$ was added successively to a stirred aqueous mixture of hydrazine hydrate $98 \%(0.107 \mathrm{~g}, 2 \mathrm{mmol})$, ethyl acetoacetate $(0.260 \mathrm{~g}, 2 \mathrm{mmol})$ and 2-hydroxy benzaldehyde ( $2 \mathrm{mmol}$ ), at ambient temperature under an open atmosphere with vigorous stirring for 5-10 min. The precipitated solid was filtered, washed with water and then with $5 \mathrm{~mL}$ of ethyl acetate/hexane mixture (1:1) to provide a pure product.

Ranu and his group (Chatterjee, Bhadra, \& Ranu, 2011) developed an efficient, convenient, one-pot and green procedure for condensation of aryl diazonium fluoroborate, carbon disulfide and amine for the synthesis
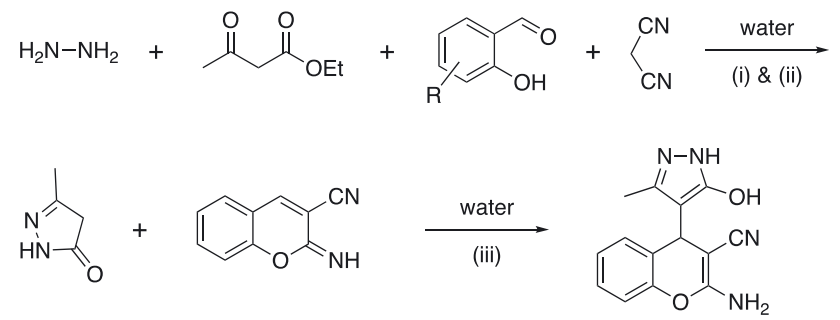

Figure 13: Proposed reaction pathway. 
of S-aryl dithiocarbamates (Figure 14). The reaction took place in water at room temperature and in the absence of any transition metal catalyst. Organic dithiocarbamates are of potential as valuable synthetic intermediates (Mukherjee \& Ashare, 1991), protecting groups in peptide synthesis (Greene \& Wuts, 1999), their occurrence in a range of biologically active compounds (Dhooghe \& De Kime, 2006), their biological properties (Ronconi et al., 2006), and vital roles in agriculture (Rafin et al., 2000).

A wide-range of substituted phenyl diazonium tetrafluoroborates reacted with carbon disulfide, cyclic and open chain amines, by this protocol to furnish the corresponding dithiocarbamates. The representative compounds are summarized in Figure 14. A range of electron-donating and electron-withdrawing substituents, such as $\mathrm{CH}_{3}, \mathrm{OMe}, \mathrm{NO}_{2}$ and $\mathrm{COMe}$ are compatible in this reaction. Cyclic and open chain amines furnished equally good yields of products. In general, the reactions are very clean, high yielding and no side product was isolated. The reactions were scaled up to multigram quantities providing similar results. The starting diazonium fluoroborates were prepared easily from the corresponding anilines by diazotization, followed by quenching with sodium tetrafluoroborate. The entire process did not involve any hazardous organic solvent.

It is suggested that the reaction proceeds via an $\mathrm{S}_{\mathrm{N}} 2 \mathrm{Ar}$ pathway, which is preferred over the uni-molecular $\mathrm{S}_{\mathrm{N}} 1$ reaction in water. The in situ-generated dithiocarbamate unit attacks $\mathrm{C}-1$ of the aryl diazonium salt to form transient intermediate 2, which through $\mathrm{N}_{2}$ elimination, forms the S-aryl dithiocarbamate (Figure 15).

Representative experimental procedure for the reaction of piperidine, $\mathrm{CS}_{\mathbf{2}}$ and phenyl diazonium tetrafluoroborate: Piperidine $(102 \mathrm{mg}, 1.2 \mathrm{mmol})$ was added drop-wise at $0-5^{\circ} \mathrm{C}$ to a well-stirred suspension of carbon disulfide $(190 \mathrm{mg}, 2.5 \mathrm{mmol})$ in water $(2 \mathrm{~mL})$. After stirring for $5 \mathrm{~min}$, phenyl diazonium tetrafluoroborate $(192 \mathrm{mg}, 1 \mathrm{mmol})$ was added and the reaction mixture was stirred at room temperature $\left(25^{\circ} \mathrm{C}\right)$ for $3 \mathrm{~h}$ (TLC). The water layer was decanted and the residue was purified by simple crystallization from ethanol to provide the corresponding dithiocarbamate, piperidine-1-carbodithioic acid phenyl ester, as a white solid (201.77 mg, 85\%), m.p. $113-116^{\circ} \mathrm{C}$.

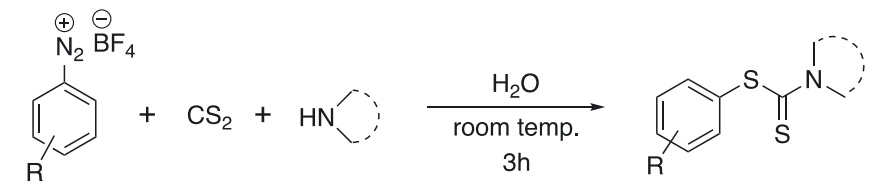

Selective Examples<smiles>S=C(Sc1ccccc1)N1CCCCC1</smiles><smiles>CCN(CC)C(=S)Sc1ccccc1</smiles><smiles>Cc1ccc(SC(=S)N2CCOCC2)cc1</smiles><smiles>COc1ccc(SC(=S)N2CCCC2)cc1</smiles><smiles>CN(C)C(=S)Sc1ccccc1[N+](=O)[O-]</smiles>
$74 \%$<smiles>O=[N+]([O-])c1ccc(SC(=S)N2CCSCC2)cc1</smiles><smiles>CC(=O)c1cccc(SC(=S)N2CCCCC2)c1</smiles><smiles>CC(=O)c1cccc(SC(=S)N2CCOCC2)c1</smiles>

Figure 14: Transition metal-free coupling of aryl diazonium tetrafluoroborate with dithiocarbamate anions.

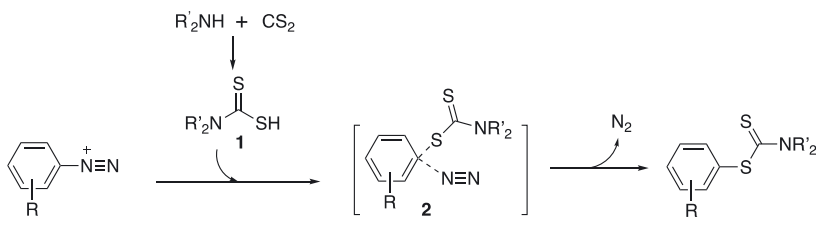

Figure 15: Proposed reaction pathway. 
Zonouz et al. described an efficient and green one-pot protocol for the synthesis of methyl 6-amino5-cyano-4-aryl-2,4-dihydropyrano[2,3-c]pyrazole-3-carboxylates by a four-component reaction of aromatic aldehydes, malononitrile, hydrazine hydrate and dimethyl acetylene dicarboxylate in water without any catalyst (Figure 16) (Zonouz, Eskandari, \& Khavasi, 2012). Pyranopyrazoles are fused heterocyclic compounds that exhibit anti-inflammatory (Zaki, Soliman, Hiekal, \& Rashad, 2006), fungicidal (Feurer et al., 2004), antiviral activities (Nasr \& Gineinah, 2002), and act as hypotensive, hypoglycemic and anticancer agents (Nadia, Nahed, Fahmyb, \& El-Sayeda, 2010). A variety of aromatic aldehydes participated in this reaction and provided the corresponding products in good yields.

Typical procedure for the synthesis of methyl 6-amino-5-cyano-4-phenyl-2,4-dihydropyrano[2,3-c] pyrazole-3-carboxylate: A mixture of malononitrile $(0.066 \mathrm{~g}, 1 \mathrm{mmol})$ and benzaldehyde $(0.1 \mathrm{~mL}, 1 \mathrm{mmol})$ in $\mathrm{H}_{2} \mathrm{O}\left(3 \mathrm{~mL}\right.$ ) was stirred at $55-60^{\circ} \mathrm{C}$ under an open atmosphere for $1 \mathrm{~h}$. Next, a mixture of hydrazine hydrate $(96 \%, 0.05 \mathrm{~mL}, 1 \mathrm{mmol})$ and dimethyl acetylene dicarboxylate $(0.14 \mathrm{~mL}, 1.2 \mathrm{mmol})$ were added and the combined reaction mixture was stirred until completion of the reaction as indicated by TLC (30 min). After cooling, the precipitated solid was filtered, washed with $\mathrm{H}_{2} \mathrm{O}$, and recrystallized from EtOH to provide the product as white crystals. yield: $0.232 \mathrm{~g}(78 \%)$; m.p. $231-232^{\circ} \mathrm{C}$.

\section{Solvent free reactions}

Solvent free reactions save resources and thus, are of great interest in synthesis as well as for cost effectivity (Tanaka \& Toda, 2000; Zangade \& Patil, 2019). The organic solvents, in general are toxic and thus pose severe health hazard to the workers, and lead to environmental pollution in the locality. Thus a large number of solvent free reactions have been developed in recent times. In this section, a few representative solvent-free procedures under stirring and grinding (Clark \& Macquarrie, 2002) have been illustrated.

Ranu et al. developed an efficient, cost-effective, simple, and green procedure for the synthesis of dihydropyrimidinones by a catalyst-free and solvent-free Biginelli's condensation of 1,3-dicarbonyl compound, aldehyde, and urea (Figure 17) (Ranu et al., 2002). This protocol of direct reaction in neat condition without solvent and catalyst demonstrates a new trend in green synthesis. A wide-range of structurally diverse 1,3-dicarbonyl compounds, aldehydes, and urea are exposed under this method to yield the corresponding dihydropyrimidinones. The results with a few representative examples are reported in Figure 17. Thiourea also works well to give the corresponding thio-derivatives, which are also of much interest with regard to biological activity. The reaction can be scaled up to kilogram quantities with a suitable reaction vessel and device.

Representative experimental procedure: A mixture of ethyl acetoacetate (freshly distilled, $260 \mathrm{mg}$, $2 \mathrm{mmol}$ ), 3-methoxybenzaldehyde (freshly distilled, $272 \mathrm{mg}, 2 \mathrm{mmol}$ ), and urea (180 mg, $3 \mathrm{mmol}$ ) was heated under stirring at $100-105^{\circ} \mathrm{C}$ (oil bath). After a few minutes of the reaction the solid started to separate out and after completion ( $1 \mathrm{~h}, \mathrm{TLC}$ ) the resulting solid was crushed, washed with cold water, filtered, and dried under vacuum to give the crude product which is reasonably pure ( $>95 \%$ purity by ${ }^{1} \mathrm{H}$ NMR). Recrystallization from hot ethanol provides the analytically pure product (476 mg, 82\%), m.p. $207-208^{\circ} \mathrm{C}$.
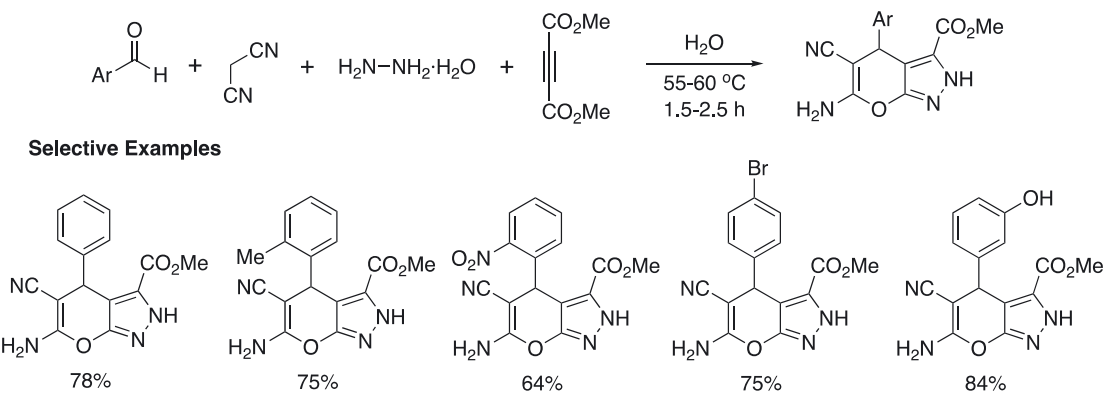

Figure 16: Synthesis of 3-methyl carboxylate substituted pyrano[2,3-c]pyrazoles via a four-component reaction. 


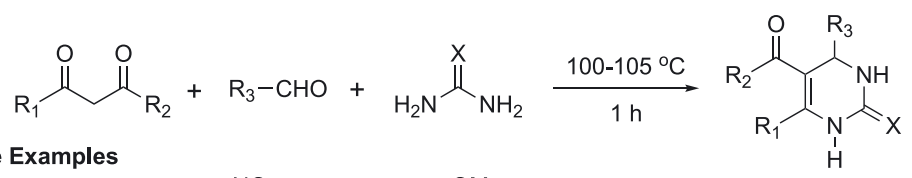

Selective Examples<smiles>CCOC(=O)C1=C(C)N(C)C(=O)NC1c1ccc(OC(C)(C)C)cc1</smiles><smiles>CCCC1NC(=O)NC(C)C1C(=O)OCC</smiles><smiles>CC(=O)C1=C(C)NC(=O)NC1c1ccccn1</smiles><smiles>CC(=O)C1=C(C)NC(=O)NC1c1ccco1</smiles><smiles>CCOC(=O)C1=C([N+](=O)[O-])NC(=S)NC1c1cccc(OC)c1</smiles><smiles>CC(=O)C1=C(C)NC(=S)NC1c1ccccc1</smiles><smiles>Cc1ccccc1-c1ccccc1</smiles>

Figure 17: Synthesis of dihydropyrimidinones without any solvent and catalyst.

A solvent- and catalyst-free tandem multicomponent reaction for the green synthesis of 1,4- dihydropyridines using amines, diethyl acetylene dicarboxylate, aldehydes and malononitrile/ethyl cyanoacetate has been developed under grinding in the absence of any solvent and catalyst (Figure 18) (Kumar \& Sharma, 2011).

A probable mechanistic route is shown in Figure 19. Primarily, coupling of the aldehyde with the active methylene compound, and the aza-Michael reaction of diethyl acetylene dicarboxylate and aniline occur under catalyst-free conditions. Rearrangement of the intermediates provided the desired product.

General experimental procedure for synthesis of 1,4-dihydropyridines: A mixture of the appropriate aldehyde ( $1 \mathrm{mmol})$, malanonitrile ( $1 \mathrm{mmol})$, aniline ( $1 \mathrm{mmol})$, and diethyl acetylene dicarboxylate $(1 \mathrm{mmol})$ was ground in a mortar and pestle at room temperature. After a few minutes a syrupy solution was found, which solidified in course of time upon completion of the reaction. The solid residue was recrystallized from ethanol to provide the pure product.

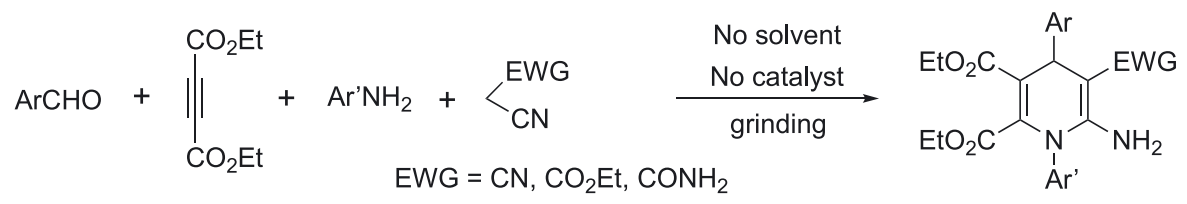<smiles>CCOC(=O)C1=C(C(=O)OCC)N(c2ccccc2)C(N)=C(C#N)C1c1ccccc1</smiles><smiles>CCOC(=O)C1=C(C(=O)OCC)N(c2ccc(Cl)cc2)C(N)=C(C#N)C1c1ccc(OC)cc1</smiles><smiles>CCOC(=O)C1=C(C(=O)OCC)N(c2ccc(Br)cc2)C(N)=C(C#N)C1c1ccc(Cl)cc1</smiles><smiles>CCOC(=O)C1=C(N)N(c2ccc([N+](=O)[O-])cc2)C(C(=O)OCC)=C(C(=O)OCC)C1c1ccc([N+](=O)[O-])cc1</smiles><smiles>CCOC(=O)C1=C(C(=O)OCC)N(c2ccc(Cl)cc2)C(N)=C(C(N)=O)C1c1ccc(Cl)cc1</smiles>

Figure 18: Solvent- and catalyst-free domino synthesis of 1,4-dihydropyridines. 


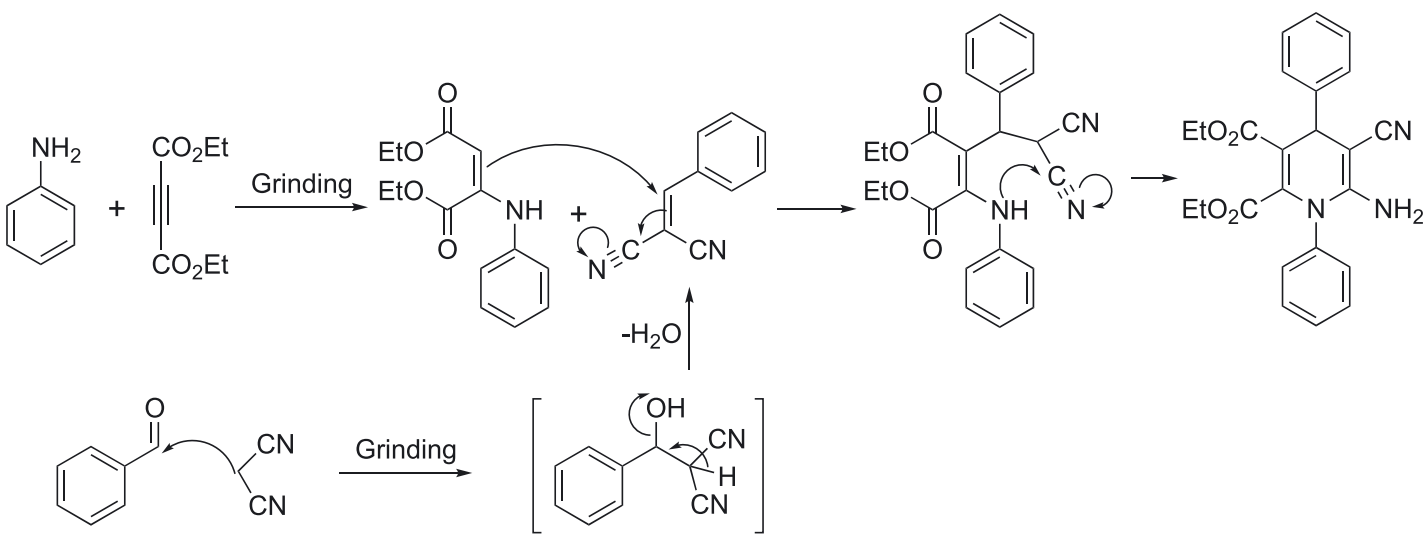

Figure 19: Possible mechanistic pathway for the synthesis of 1,4-dihydropyridines.

Rong et al. reported a one-pot, facile and efficient method for the synthesis of 3-amino-2,4-dicarbonitrile5 -methylbiphenyl by a three-component reaction of an aromatic aldehyde, malononitrile and acetone under solvent-free grinding conditions (Figure 20) (Rong, Han, Jiang, Shi, \& Tu, 2008).

Compared with the conventional reaction, this synthetic process offers the advantages of ease of setup, mild reaction conditions, excellent yields and environmental acceptability.

General procedure for the synthesis of 3-amino-2,4-dicarbonitrile-5-methylbiphenyl: A mixture of an aromatic aldehyde ( $2 \mathrm{mmol})$, malononitrile $(5 \mathrm{mmol})$, acetone $(5 \mathrm{mmol})$, and $\mathrm{NaOH}$ (1.5 equivalents) was ground in a mortar with a pestle at room temperature. The reaction was completed in $2-5 \mathrm{~min}$ (TLC), and the reaction mixture was poured into water. The product was filtered, dried, and recrystallized from $95 \%$ ethanol, m.p.: $182-184^{\circ} \mathrm{C}$.

Quinolines containing 1,4-dihydropyridine unit are of much importance as they are used as antiinflammatory, antibacterial, antimalarial, anti-asthamatic, and tyrosine kinase inhibiting agents (Chen, Fang, Sheu, Hsu, \& Tzeng, 2001; Roma, Braccio, Grossi, \& Chia, 2000). An effective synthesis of polyhydroquinolines was accomplished via a one-pot four-component reaction of aldehydes, dimedone, active methylene compounds, and ammonium acetate under solvent-free grinding at room temperature (Figure 21) (Kumar, Sharma, Kapoor, \& Hundal, 2008). It was found that electron deficient and electron rich aldehydes as well as heterocyclic aldehyde such as thiophene-2-carboxaldehyde, reacted easily with $\beta$-ketoesters to furnish high yields of products. This method does not require any hazardous catalyst or organic solvent. The key advantages of this protocol are the high yields, short reaction time, simple workup, and purification of products by simple recrystallization from ethanol.

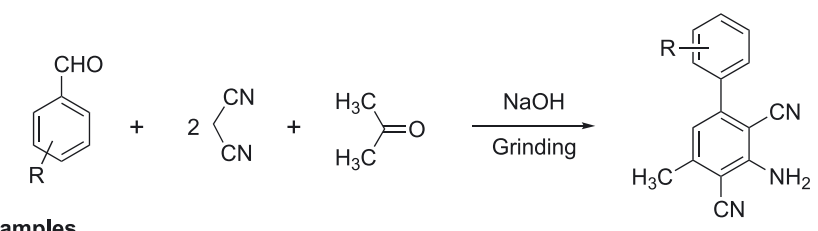

Selective Examples<smiles>Cc1cc(-c2ccccc2)c(C#N)c(N)c1C#N</smiles><smiles>COc1ccc(-c2cc(C)c(C#N)c(N)c2C#N)cc1</smiles><smiles>Cc1cc(-c2ccc(Cl)cc2)c(C#N)c(N)c1[N+](=O)[O-]</smiles><smiles>Cc1cc(-c2ccc(Br)cc2)c(C#N)c(N)c1[N+](=O)[O-]</smiles><smiles>Cc1cc(-c2ccc(F)cc2)c(C#N)c(N)c1[N+](=O)[O-]</smiles>

Figure 20: Synthesis of 3-amino-2,4-dicarbonitrile-5-methylbiphenyl by a grinding method. 


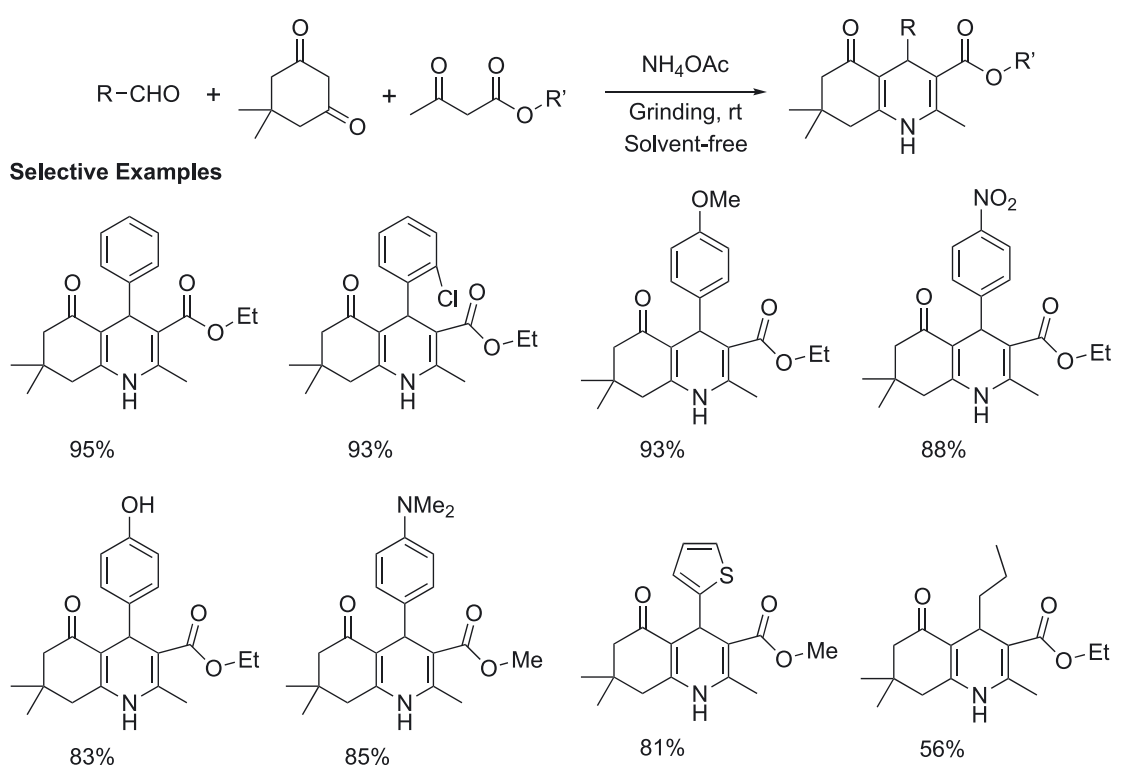

Figure 21: Synthesis of polyhydroxyquinolines on grinding.

Representative procedure for the synthesis of ethyl-1,4,7,8-tetrahydro-2,7,7-trimethyl-4(2-chlorolphenyl)-5(6H)-oxoquinolin-3-carboxylate: A mixture of aldehyde 1 (2 mmol), dimedone 2 $(2 \mathrm{mmol}), \beta$-ketoester $3(2 \mathrm{mmol})$, and ammonium acetate $(3 \mathrm{mmol})$ was uniformly ground in a mortar with a pestle till the completion of reaction as indicated by TLC (10-20 min). The resultant material was washed with water to remove any unreacted ammonium acetate and was air-dried to afford the crude product. The pure product was obtained by recrystallization from ethyl alcohol as a yellow solid, m.p. $207-208^{\circ} \mathrm{C}$.

\section{Conclusions}

The practice of Green Chemistry in a chemical process is of prime importance in the context of rising environmental issues. This awareness among the all section of chemists, particularly the young ones is very much needed. With this objective, we have introduced the basic understanding of Green Chemistry through a natural process, photosynthesis and illustrated the principles of Green Chemistry by analysis of this reaction. A few representative reactions based on the green parameters of photosynthesis such as use of visible light (sunlight, LED) as energy source, water as reaction medium and no use of hazardous organic solvent have been demonstrated with detailed experimental procedures. The significant advantages of these methods are high efficiency, atom economy, cost effectiveness, safety and sustainability. We believe that this article will attract the attention of chemical community towards practice of green chemistry in all types of synthesis.

Author contributions: All the authors have received role for the content of this submitted manuscript and approved for submission.

Research funding: B. C. Ranu gratefully acknowledges the support of Indian National Science Academy, New Delhi with an offer of the position of INSA Honorary Scientist to him. L. Adak thanks SERB, DST, Government of India (Project: SRG/2020/001350) and the WBDST-BT for their support via government order [Memo No: 1854 (Sanc.)/ST/P/S\&T/15G-7/2019]. T. Ghosh thanks to UGC-DSKPDF (UGC Award Letter No. \& Date: F.4-2/2006 (BSR)/CH/19-20/0088; 24.01.2020) for his postdoctoral fellowship.

Conflict of interest statement: The authors declare no conflicts of interest regarding this article. 


\section{References}

Ahluwalia, V. K. (2013). Green chemistry: A textbook. Alpha Science International, 1-568.

Azizi, N., \& Saidi, M. R. (2004). $\mathrm{LiClO}_{4}$ accelerated Michael addition of amines to $\alpha, \beta$-unsaturated olefins under solvent-free conditions. Tetrahedron, 60, 383-387.

Bachmann, W. E. (1934). Benzopinacol. Organic Syntheses, 14, 8.

Ball, P. (2000). $\mathrm{H}_{2} \mathrm{O}: \mathrm{A}$ biography of water. London: Phoenix Press.

Bartolomeu, A. A., Silva, R. C., Brocksom, T. J., Noël, T., \& Oliveira, K. T. (2019). Photoarylation of pyridines using aryldiazonium slts and visible light: An EDA approach. The Journal of Organic Chemistry, 84, 10459-10471.

Basu, B., Das, P., \& Hossain, I. (2004). Synthesis of $\beta$-amino esters via aza-Michael addition of amines to alkenes promoted on silica: A useful and recyclable surface. Synlett, 2630-2632. https://doi.org/10.1055/s-2004-834836.

Breslow, R. (1991). Hydrophobic effects on simple organic reactions in water. Accounts of Chemical Research, 24, 159-164.

Bryan, M. C., Dunn, P. J., Entwistle, D., Gallou, F., Koenig, S. G., Hayler, J. D., ... Weiberth, F. J. (2018). Key green chemistry research areas from a pharmaceutical manufacturers' perspective revisited. Green Chemistry, 20, 5082-5103.

Cardillo, G., \& Tomasini, C. (1996). Asymmetric synthesis of $\beta$-amino acids and $\alpha$-substituted $\beta$-amino acids. Chemical Society Reviews, 25, 117-128.

Chatterjee, T., Bhadra, S., \& Ranu, B. C. (2011). Transition metal-free procedure for the synthesis of S-aryl dithiocarbamates using aryl diazonium fluoroborate in water at room temperature. Green Chemistry, 13, 1837-1842.

Chen, Y. L., Fang, K.-C., Sheu, J.-Y., Hsu, S.-L., \& Tzeng, C.-C. (2001). Synthesis and antibacterial evaluation of certain quinolone derivatives. Journal of Medicinal Chemistry, 44, 2374-2377.

Chen, S., Zhong, Q., Zhu, H., Liu, C., Zhuang, P., \& Sun, W. (2020). Visible-light-induced C-C coupling reaction to synthesize bipyridine from 3-cyano-1,4-dihydropyridines. Frontiers in Chemistry, 7, 940.

Clark, J. H., \& Macquarrie, D. (2002). Handbook of green chemistry and technology (1st ed.). Oxford: Wiley and Blackwell.

Cohen, I., Mishra, A. K., Parvari, G., Edrei, R., Dantus, M., Yoav Eichen, Y., ... Szpilman, A. M. (2017). Sunlight assisted direct amide formation via a charge-transfer complex. Chemical Communications, 53, 10128-10131.

Cortes-Clerget, M., Yu, J., Kincaid, J. R. A., Walde, P., Gallou, F., \& Lipshutz, B. H. (2021). Water as the reaction medium in organic chemistry: From our worst enemy to our best friend. Chemical Science, 12, 4237-4266.

Deligeorgiev, T., Gadjev, N., Vasilev, A., Kaloyanova, S., Vaquero, J. J., \& Alvarez-Builla, J. (2010). Green chemistry in organic synthesis. Mini-Reviews in Organic Chemistry, 7, 44-53.

Dhooghe, M., \& De Kime, N. (2006). Synthetic approaches towards 2-iminothiazolidines: An overview. Tetrahedron, 62, 513-535.

Douglas, J. J., Sevrin, M. J., \& Stephenson, C. R. J. (2016). Visible light photocatalysis: Applications and new disconnections in the synthesis of pharmaceutical agents. Organic Process Research \& Development, 20, 1134-1147.

Ellis, G. P. (1997). Chromenes, chromanones and chromones-introduction. In Weissberger, A., \& Taylor, E. C. (Eds.), The chemistry of heterocyclic compounds: Chromenes, chromanes and chromones. New York: Wiley. ch. I.

Festa, A. A., Voskressensky, L. G., \& Van der Eycken, E. V. (2019). Visible light-mediated chemistry of indoles and related heterocycles. Chemical Society Reviews, 48, 4401-4423.

Feurer, A., Luithle, J., Wirtz, S., Koenig, G., Stasch, J., Stahl, E., ... Lang, D. (2004). Bayer Healthcare AG, Germany, PCT Int. Appl., WO 2004009589. Chemical Abstracts, 140, 146157.

Greene, T. W., \& Wuts, P. G. M. (1999). Protecting groups in organic synthesis (3rd ed., p. 484). New York: Wiley Interscience.

Kärkäs, M. D., Porco, J. A., \& Stephenson, C. R. J. (2016). Photochemical approaches to complex chemotypes: Applications in natural product synthesis. Chemical Reviews, 116, 9683-9747.

Kitanosono, T., Masuda, K., Xu, P., \& Kobayashi, S. (2018). Catalytic organic reactions in water toward sustainable society. Chemical Reviews, 118, 679-746.

Kumaravel, K., \& Vasuki, G. (2009). Four-component catalyst-free reaction in water: Combinatorial library synthesis of novel 2-amino-4-(5-hydroxy-3-methyl-1H-pyrazol-4-yl)-4H-chromene-3-carbonitrile derivatives. Green Chemistry, 11, $1945-1947$.

Kumar, A., \& Sharma, S. (2011). A grinding-induced catalyst- and solvent-free synthesis of highly functionalized 1,4-dihydropyridines via a domino multicomponent reaction. Green Chemistry, 13, 2017-2020.

Kumar, S., Sharma, P., Kapoor, K. K., \& Hundal, M. S. (2008). An efficient, catalyst- and solvent- free, four-component, and one-pot synthesis of polyhydroquinolines on grinding. Tetrahedron, 64, 536-542.

Lampman, P. D. L., \& Chriz, G. M. (1982). Introduction to organic lab technique (p. 412). New York: College Publishing.

Li, C. J. (1993). Organic reactions in aqueous media-with a focus on carbon-carbon bond formation. Chemical Reviews, 93, 2023-2035.

Li, C.-J., \& Chen, L. (2006). Organic chemistry in water. Chemical Society Reviews, 35, 68-82.

Lindstrom, U. M. (2002). Stereoselective organic reactions in water. Chemical Reviews, 102, 2751-2772.

Li, P., Terrett, J. A., \& Zbieg, J. R. (2020). Visible-light photocatalysis as an enabling technology for drug discovery: A paradigm shift for chemical reactivity. ACS Medicinal Chemistry Letters, 11, 2120-2130.

Li, W., Xu, W., Xie, J., Yu, S., \& Zhu, C. (2018). Distal radical migration strategy: An emerging synthetic means. Chemical Society Reviews, 47, 654-667. 
Loh, T. P., \& Wie, L. L. (1998). Indium trichloride-catalyzed conjugate addition of amines to $\alpha, \beta$ - ethylenic compounds in water. Synlett, 975-976. https://doi.org/10.1055/s-1998-1845.

Mukherjee, A. K., \& Ashare, R. (1991). Isothiocyanates in the chemistry of heterocycles. Chemical Reviews, 91, 1-24.

Nadia, M. R., Nahed, Y. K., Fahmyb, A., \& El-Sayeda, A. A. F. (2010). Facile synthesis of fused nitrogen containing heterocycles as anticancer agents. Pharma Chem, 2, 400-417.

Narayan, S., Muldoon, J., Finn, M. G., Fokin, V. V., Kolb, H. C., \& Sharpless, K. B. (2005). “On water”: Unique reactivity of organic compounds in aqueous suspension. Angewandte Chemie International Edition, 44, 3275-3279.

Nasr, M. N., \& Gineinah, M. M. (2002). Pyrido[2,3- $d]$ pyrimidines and pyrimido $\left[5^{\prime}, 4^{\prime}: 5,6\right]$ pyrido[2,3- $\left.d\right]$ pyrimidines as new antiviral agents: Synthesis and biological activity. Archiv der Pharmazie: An International Journal Pharmaceutical and Medicinal Chemistry, 335, 289.

Rafin, C., Veignie, E., Sancholle, M., Postal, D., Len, C., Villa, P., ... Ronco, G. (2000). Synthesis and antifungal activity of novel bisdithiocarbamate derivatives of carbohydrates against Fusarium oxysporum f. sp. Lini. Journal of Agricultural and Food Chemistry, 48, 5283-5287.

Ranu, B. C., \& Banerjee, S. (2007). Significant rate acceleration of the aza-Michael reaction in water. Tetrahedron Letters, 48 , 141-143.

Ranu, B. C., Hajra, A., \& Dey, S. S. (2002). A practical and green approach towards synthesis of dihydropyrimidinones without any solvent or catalyst. Organic Process Research \& Development, 6, 817-818.

Reboule, I., Gil, R., \& Collin, J. (2005). Aza-Michael reactions catalyzed by samarium diiodide. Tetrahedron Letters, 46, $7761-7764$.

Riddick, J. A., Bunger, W. B., \& Sakano, T. K. (1986). Organic solvents: Physical properties and methods of purification. New York: Wiley.

Rideout, D. C., \& Breslow, R. (1980). Hydrophobic acceleration of Diels-Alder reactions. Journal of the American Chemical Society, 102, 7816-7817.

Roma, G., Braccio, M. D., Grossi, G., \& Chia, M. (2000). 1,8-Naphthyridines IV. 9-Substituted N,N-dialkyl-5-(alkylamino or cycloalkylamino) $[1,2,4]$ triazolo[4,3-a][1,8]naphthyridine-6-carboxamides, new compounds with anti-aggressive and potent anti-inflammatory activities. European Journal of Medicinal Chemistry, 35, 1021-1035.

Ronconi, L., Marzano, C., Zanello, P., Corsini, M., Miolo, G., Macca, C., ... Fregona, D. (2006). Gold(III) dithiocarbamate derivatives for the treatment of cancer: Solution chemistry, DNA binding, and hemolytic properties. Journal of Medicinal Chemistry, 49, $1648-1657$.

Rong, L., Han, H., Jiang, H., Shi, D., \& Tu, S. (2008). Solvent-free synthesis of 3-amino-2,4-dicarbonitrile-5-methylbiphenyl by a grinding method. Synthetic Communications, 38, 1044-1050.

Ruiz-Lopez, M. F., Francisco, J. S., Martins-Costa, M. T. C., \& Anglada, J. M. (2020). Molecular reactions at aqueous interfaces. Nature Reviews Chemistry, 4, 459-475.

Sarkar, A., Santra, S., Kundu, S. K., Hajra, A., Zyryanov, G. V., Chupakhin, O. N., ... Majee, A. (2016). A decade update on solvent and catalyst-free neat organic reactions: A step forward towards sustainability. Green Chemistry, 18, 4475-4525.

Silvi, M., \& Melchiorre, P. (2018). Enhancing the potential of enantioselective organocatalysis with light. Nature, 554, 41-49.

Skubi, K. L., Blum, T. R., \& Yoon, T. P. (2016). Dual catalysis strategies in photochemical synthesis. Chemical Reviews, 116, 10035-10074.

Surendra, K., Krishnaveni, N. S., Sridhar, R., \& Rao, K. R. (2006). $\beta$-Cyclodextrin promoted aza-Michael addition of amines to conjugated alkenes in water. Tetrahedron Letters, 47, 2125-2127.

Tanaka, K., \& Toda, F. (2000). Solvent-free organic synthesis. Chemical Reviews, 100, 1025-1074.

Tang, S. L. Y., Smith, R. L., \& Poliakoff, M. (2005). Principles of green chemistry: Productively. Green Chemistry, 7, 761-762.

Varala, R., Alam, M. M., \& Adapa, S. R. (2003). Chemoselective Michael type addition of aliphatic amines to $\alpha$, $\beta$-ethylenic compounds using bismuth triflate catalyst. Synlett, 720-722. https://doi.org/10.1002/chin.200331055.

Xu, L.-W., Li, J.-W., Zhou, S.-L., \& Xia, C.-G. (2004). A green, ionic liquid and quaternary ammonium salt-catalyzed aza-Michael reaction of $\alpha, \beta$-ethylenic compounds with amines in water. New Journal of Chemistry, 28, 183-184.

Zaki, M. E. A., Soliman, H. A., Hiekal, O. A., \& Rashad, A. E. (2006). Pyrazolopyranopyrimidines as a class of anti-inflammatory agents. Zeitschrift für Naturforschung C, 61, 1-5.

Zangade, S., \& Patil, P. (2019). A review on solvent-free methods in organic synthesis. Current Organic Chemistry, 23, 2295-2318.

Zonouz, A. M., Eskandari, I., \& Khavasi, H. R. (2012). A green and convenient approach for the synthesis of methyl 6-amino-5-cyano4-aryl-2,4-dihydropyrano[2,3-c]pyrazole-3- carboxylates via a one-pot, multi-component reaction in water. Tetrahedron Letters, 53, 5519-5522. 